\title{
Two-body wear rate of PEEK, CAD/CAM resin composite and PMMA: Effect of specimen geometries, antagonist materials and test set-up configuration
}

\author{
Wimmer, Timea ; Huffmann, Anne Mildred Sophie ; Eichberger, Marlis ; Schmidlin, Patrick R ; \\ Stawarczyk, Bogna
}

DOI: https://doi.org/10.1016/j.dental.2016.03.005

Posted at the Zurich Open Repository and Archive, University of Zurich

ZORA URL: https://doi.org/10.5167/uzh-130263

Journal Article

Accepted Version

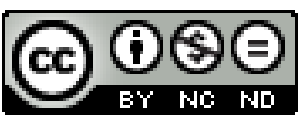

The following work is licensed under a Creative Commons: Attribution-NonCommercial-NoDerivatives 4.0 International (CC BY-NC-ND 4.0) License.

Originally published at:

Wimmer, Timea; Huffmann, Anne Mildred Sophie; Eichberger, Marlis; Schmidlin, Patrick R; Stawarczyk, Bogna (2016). Two-body wear rate of PEEK, CAD/CAM resin composite and PMMA: Effect of specimen geometries, antagonist materials and test set-up configuration. Dental Materials, 32(6):e127-e136.

DOI: https://doi.org/10.1016/j.dental.2016.03.005 
Two-body wear rate of PEEK, CAD/CAM resin composite and PMMA: Effect of specimen geometries, antagonist materials and test set-up configuration

Timea Wimmer ${ }^{1}$, Anne Mildred Sophie Huffmann ${ }^{1}$, Marlis Eichberger ${ }^{1}$, Patrick R. Schmidlin ${ }^{2}$, Bogna Stawarczyk ${ }^{1}$

\section{Authors`affiliations}

${ }^{1}$ Department of Prosthodontics, Dental School, Ludwig-Maximilians-University Munich, Goethestrasse 70, 80336 Munich, Germany

${ }^{2}$ Clinic of Preventive Dentistry, Periodontology and Cariology, Center of Dental Medicine, University of Zurich, Plattenstrasse 11, 8032 Zurich, Switzerland

\section{Corresponding Author details:}

Dr. rer. biol. hum. Dipl.-Ing. (FH) Bogna Stawarczyk, MSc

Department of Prosthodontics, Dental School, Ludwig-Maximilians-University Munich, Goethestrasse 70, 80336 Munich, GERMANY

Tel.: +49 89440059573

Fax: +49 89440059502

Email: bogna.stawarczyk@med.uni-muenchen.de

Keywords: PEEK, composite, CAD/CAM, two-body wear, enamel, crown, flat specimens 
Two-body wear rate of PEEK, CAD/CAM resin composite and PMMA: Effect of specimen geometries, antagonist materials and test set-up configuration

\section{ABSTRACT}

Objectives. To test and compare the two-body wear rate of three CAD/CAM polymer materials and the influence of specimen geometry, antagonist material and test setup configuration.

Methods. Three CAD/CAM polymeric materials were assessed: A thermoplastic polyetheretherketone (PEEK), an experimental nanohybrid composite (COMP) and a PMMA-based material (PMMA). Crown-shaped and flat specimens were prepared from each material. The specimens underwent thermo-mechanical loading (50 N, $5 / 55^{\circ} \mathrm{C} ; 600,000$ chewing cycles) opposed to human enamel and stainless steel antagonists. Half of the specimens of each group were loaded with a sliding movement of $0.7 \mathrm{~mm}$, the remaining half without. Thereby, 24 different test set-ups were investigated $(n=12)$. Wear of the materials and antagonists was evaluated with a match-3D procedure. The topography of all surfaces was examined with scanning electron microscopy (SEM). Data were statistically evaluated with four-/one-way ANOVA followed by Scheffé post-hoc test and unpaired t-test $(p<0.05)$.

Results. All PEEK specimens showed significantly less material loss than COMP and PMMA specimens when loaded laterally. Within the axial loaded groups this was only true for the flat specimens tested with enamel antagonists. Crown specimens of these groups exhibited lower loss values than flat ones. Lateral force application led mostly to significantly higher material loss than the axial load application. On the antagonist side, no impact of CAD/CAM polymer material, antagonist material, force application and specimen geometry was found.

Significance. Wear of PEEK was lower than that of the resin-based materials when lateral forces were applied, but showed comparable antagonist wear rates at the same time. 


\section{Introduction}

Computer-aided design/computer-aided manufacturing (CAD/CAM) technique allows milling of different materials with high precision. Because the demand for metal-free treatment options in dentistry is still increasing, several CAD/CAM polymers have been introduced for dental restorations alternatively to ceramics [1]. The actually growing interest in tooth-colored high-performance polymers can be also attributed to improvements in CAD/CAM-technology, faster processing and lower costs as well as improved mechanical properties in combination with the advantage of using them in thinner thicknesses as compared to ceramics [2-6]. However, CAD/CAM polymeric materials such as composite- and PMMA-based materials are still rather used as long-term provisionals and are more and more considered for definitive restorations $[5,6]$. Several studies investigated the performance of CAD/CAM resin FDPs regarding color stability and mechanical properties and obtained comparable or even better results as compared to glass-ceramics [6-9].

In contrast to ceramics, the major advantage of polymers is the low elastic modulus, which allows for better absorption of functional stresses by deformation [9]. Another advantage is the low abrasiveness of the enamel antagonists $[3,9,10]$. Two studies assessing the wear behavior of CAD/CAM polymers and ceramics have shown that polymers generated the least amount of antagonistic enamel wear $[3,9]$. In contrast to ceramics, CAD/CAM resins caused no enamel cracks [3].

With regard to the restoration wear itself, metal alloys and ceramic materials were proven to be very wear-resistant in general [11-13]. In contrast, composite resin materials and unfilled polymers cannot withstand a more accentuated material loss $[3,12-16]$. Although the wear of ceramic materials is supposed to be similar to that of enamel, there are inconsistent results indicating even more occlusal contact wear than for composites [17]. Different test set-ups or selection of subjects might be the reason for this $[16,17]$. Nonetheless, the wear of natural teeth can significantly increase with an antagonist supplied with a ceramic restoration [17]. In literature, there is a scarcity of studies dealing with the wear of resins as FDPs or veneering materials $[3,15,18]$.

A rather new polymeric material in this field of dental research is polyetheretherketone (PEEK) - a polymer from the main group PAEK (polyaryletherketone). PEEK is either available as industrially pressed blanks for 
CAD/CAM milling, as industrially pre-pressed pellets or in granular form. However, the latter two forms require thermo-pressing or melting processing. Due to the excellent physical and biological properties, PEEK has gained wide acceptance in medicine and has attracted attention in prosthodontics in recent time and has been suggested being a potential material for fixed dental prostheses (FDPs) $[19,20]$. Investigations on performance of three-unit PEEK FDPs have shown that industrial pre-fabrication of blanks (CAD/CAM/pellets) increased the stability and reliability of the restorations. Less plastic deformation and higher mean fracture loads were observed compared to FDPs pressed from granular material. Also, higher Weibull moduli were achieved [21]. Concerning the adhesion of PEEK to dimethylmethacrylates, the initial difficulties were overcome and the results obtained in studies on bond strengths of PEEK to other resins as well as on load-bearing capacity of FDPs are very promising [6,20,22-31].

In view of the limited data available on wear behavior of CAD/CAM polymer materials - especially PEEK-, the purpose of the current study was to evaluate and compare the two-body wear rate of thermoplastic PEEK, experimental CAD/CAM nanohybrid composite and PMMA-based material. Different test set-ups regarding configuration, antagonist material and force application were investigated. The null hypothesis was that the wear rate of CAD/CAM polymers and antagonists of all tested groups would be similar, regardless of the test method used. 


\section{Materials and methods}

Table 1 provides detailed information regarding the materials (composition, lot numbers and physical properties) used in this study. The test design is presented in Fig. 1. The following variables and configurations were investigated and combined:

1. Materials: $\quad$ Thermoplastic PEEK (Dentokeep, nt-trading, Karlsruhe, Germany; LOT: 11DK14001) experimental CAD/CAM nanohybrid composite (Ivoclar Vivadent, Schaan, Lichtenstein; LOT: HT A2/C14 28923)

PMMA-based CAD/CAM material (artBloc Temp, Merz Dental, Lütjenburg, Germany; LOT: 44308)

2. Configurations: Crown and flat specimens

3. Antagonists: Standardized human enamel antagonists standardized stainless steel antagonists (SD Mechatronik, Feldkirchen-Wetsterham, Germany)

4. Wear simulation: With lateral movement

Without lateral movement (axial)

Based on the above mentioned variables and configurations, a total of 24 different test groups were evaluated. Each group consisted of 12 specimens. To avoid any operator bias and ensure constant quality, specimens were made by one qualified technician, who was unaware of the study design and aims.

\section{Fabrication of flat specimens}

Flat specimens of the three different materials were manufactured by cutting standardized geometries of $10 \mathrm{~mm}$ length, $0.5 \mathrm{~mm}$ width and a thickness of $2 \mathrm{~mm}$ under constant water-cooling using a red handpiece (GENTLEpower LUX 25 LP, KaVo Dental, Biberach/Riß, Germany) and a diamond cutting disc (Diamand disc, 924.104.180, Komet Dental, Gebr. Brasseler, Lemgo, Germany). The specimens were then embedded in an acryl resin (Scandiform/ScandiQuick, SCAN-DIA, Hagen, Germany) and polished with Silicon Carbide Paper (SiC) paper in 5 steps under water-cooling up to P4000 (P240, P500, P1200, P2400, P4000, Struers, Ballerup, Denmark and Tegramin-20, MD-Fuga 200 mm, Struers). 


\section{Fabrication of crown specimens}

A standardized anatomically supported base metal alloy model (Remanium 2000, Dentaurum, Ispringen, Germany) with an elasticity modulus of $210 \mathrm{GPa}$ was used to fabricate crowns [32]. The model abutment tooth was designed according to a molar crown design utilizing a complete crown preparation with a $1.2 \mathrm{~mm}$ deep chamfer margin design, an occlusal reduction of $1.5 \mathrm{~mm}$ and a total convergence angle of $6^{\circ}$. The model was scanned and a master STL-file of the molar crown was designed (Ceramill Motion 2 System, AmannGirrbach, Koblach, Austria). The Cerec inLab system (Sirona, Bensheim, Germany) was used for the experimental CAD/CAM nanohybrid composite and PMMA-based CAD/CAM material, while the ZENO Tec System (ZENO 4030 M1, Wieland+Dental, Pforzheim, Germany) was employed for the thermoplastic PEEK.

After seating of the crowns by using occlusion spray (Arti-Spray, white, BK 285, Dr. Jean Bausch KG, Cologne, Germany), all crowns were polished under standardized conditions (Abraso-Starglanz, bredent, Senden, Germany). The inner surfaces of the crowns were air-abraded before cementation using alumina powder (10 s, 0,5 bar, distance: $10 \mathrm{~mm}$ ) with a mean particle size of $50 \mu \mathrm{m}$ (Fineblaster type FG 3, Sandmaster, Zofingen, Switzerland) and then cleaned in an ultrasonic bath filled with distilled water for $10 \mathrm{~min}$ (Sonorex, Bandelon electronic, Berlin, Germany). Subsequently, the crowns were adhesively cemented on the base metal alloy abutments using a self-adhesive resin cement (Clearfil SA Cement, Kuraray, Tokyo, Japan) according to the manufacturer's instruction. A special cementing device was used to ensure that the crowns were centrally loaded at a standardized force of $150 \mathrm{~g}$ for $10 \mathrm{~min}$. Each specimen was light-cured from each aspect (buccal/distal/oral/mesial) for $40 \mathrm{~s}$ with a LED light-curing unit using the standard program with a light intensity of $1200 \mathrm{~mW} / \mathrm{cm}^{2}$ (Elipar S10, 3M ESPE, Seefeld, Germany). Subsequently, specimens were stored for $24 \mathrm{~h}$ in distilled water at $37^{\circ} \mathrm{C}$. Afterwards, all crown specimens were digitized. For this purpose, scan powder (MetL-Chek Developer D 70, Helling, Heidgraben, Germany) was applied to the investigated surfaces. Scanning was performed with a triangulation sensor from two different directions (Laserscan 3D, SD Mechatronik) to preserve the surface geometry before wear simulation. 


\section{Fabrication of the antagonists}

Mesiobuccal cusps of extracted human maxillary permanent molars were used as enamel antagonists. All teeth originated from an anonymous collection of several dentists in the Munich area. All teeth were disinfected by immersing them in a $0.5 \%$ chloramine solution (Chloramine-T; Sigma-Aldrich Laborchemikalien, Seelze, Germany, LOT 53110, CAS No. 7080-50-4) at room temperature for a maximum period of one week after extraction. Afterwards, they were stored in distilled water at $5{ }^{\circ} \mathrm{C}$ for a maximum time period of 6 months according to the ISO 11405/TR. Crowns were then separated to obtain mesiobuccal cusps. Subsequently, a standardized spherical cusp shape with a diameter of $1 \mathrm{~mm}$ generated using a bench drill with $40 \mu \mathrm{m}$ and $8 \mu \mathrm{m}$ grit (BT-BD $1020 \mathrm{D}$, Einhell Germany, Landau/lsar, Germany). Afterwards, specimens were polished with a goat hair brush (Abraso-Starglanz, Bredent) and embedded in a round stainless steel mold using amalgam (Dispersalloy, Dentsply DeTrey, Konstanz, Deutschland, LOT: 120823).

In addition, hemispherical stainless steel specimens (X5CrNi18-10, Steel no. k.h.s DIN 1.4301, SD Mechatronik) with an elastic modulus of $210 \mathrm{GPa}$, served as antagonists. The diameter of the cusps was $6 \mathrm{~mm}$ [32].

In order to allow optimal wear quantification and superimposition, each antagonist received three notches using a diamand disc (924.104.180, Komet Dental). Subsequently, all antagonists were digitized as described above.

\section{Wear simulation}

Specimens and antagonists were mounted in a chewing simulator (Chewing Simulator CS-4, SD Mechatronik) (Fig. 2). Each crown and each flat specimen was tested with steel and human antagonists, respectively. Half of the specimens were loaded with a vertical load of $50 \mathrm{~N}$ and a sliding movement of $0.7 \mathrm{~mm}$ for 600,000 chewing cycles whereas the other half was loaded in the same manner, but without lateral movement. During wear simulation, thermo-mechanical loading was applied in distilled water at temperatures of $5{ }^{\circ} \mathrm{C}$ and $55^{\circ} \mathrm{C}$ with duration of $60 \mathrm{~s}$ for each cycle.

After wear simulation, the surfaces of the crown specimens and all antagonists were digitized again as described above. After wear simulation, the surfaces of the crown specimens and the antagonists were digitized again as described above. The datasets before (baseline reference) and after wear simulation were superimposed using a three-notch alignment and match-3D procedure and images were generated 
displaying the differences. Material loss was computed (Debian, Match 3D, developed by Dr. Wolfram Gloger).

\section{Statistical analysis}

Data were analyzed using SPSS Version 20 (SPSS INC, Chicago, IL, USA). Firstly, descriptive statistics were calculated for the data. Normality of data distribution was tested using the Kolmogorov-Smirnov test and analysis of variance (four-way ANOVA) was performed with respect to CAD/CAM polymer materials, antagonist materials, force applications and specimen geometry. One-way ANOVA followed by Scheffé post-hoc test was used for analyze the effect of CAD/CAM polymer material. Unpaired t-test was used for calculation of impact of antagonist materials, force applications and specimens' geometry. $P$ values smaller than $5 \%$ were considered to be statistically significant in all tests. Selected surfaces of the specimens and antagonists were visually analyzed by scanning electron microscopy (SEM) (Carl Zeiss Supra 55 VP Gemini, Carl Zeiss, Oberkochen, Germany) operating at $10 \mathrm{kV}$ with a working distance of $40-50 \mathrm{~mm}$. 


\section{Results}

For the two-body wear on the material side, the four-way ANOVA indicated an interaction between all tested parameters such as CAD/CAM polymer material, antagonist material, force application and specimen geometry $(p=0.006)$. Therefore, the fixed effects of CAD/CAM polymer materials, antagonist materials, force applications and specimen geometry could not be directly compared because the higher order interactions were found to be significant. As a consequence, several different analyses had to be computed and divided by levels depending on the respective hypothesis as presented more detailed below (Table 2, 3). Fig. 3 depicts the boxplot diagrams for all groups.

\section{Impact of CAD/CAM polymer material}

Loading without lateral movement

Among flat specimens loaded with an enamel antagonist, PEEK groups showed the significantly lowest wear, followed by COMP and PMMA $(p<0.001)$. Within the remaining groups, no differences regarding material loss between CAD/CAM materials were observed $(p>0.286)$.

\section{Loading with lateral movement}

For flat and crown specimens within the enamel antagonist groups as well as for the crown specimens within the stainless steel antagonist group, PEEK showed a significantly lower material loss than PMMA and COMP $(p<0.023)$. However, no differences were observed between the two latter groups $(p=0.751)$.

Within stainless steel antagonists tested against flat specimens, PEEK also showed the least wear rate, followed by PMMA and COMP $(p<0.001)$.

Impact of antagonist material

Loading without lateral movement

Steel antagonists showed a statistically significantly higher material loss than enamel within flat COMP and PMMA specimens ( $p<0.002)$. No impact of antagonist material was observed within the crown group ( $p>0.197)$. 


\section{Loading with lateral movement}

With exception of PEEK crowns, all groups with steel antagonists presented higher material loss than enamel ones $(p<0.018)$.

\section{Impact of force application}

All groups exhibited higher material loss rates when loaded with lateral movement than without $(p=0.001)$. Exceptions of this finding were PEEK crowns loaded with steel antagonists $(p=0.518)$ and COMP crowns opposed to enamel antagonists $(p=0.256)$.

\section{Impact of specimen geometry}

Within stainless steel antagonists, flat PEEK specimens loaded with lateral movement showed significantly higher material loss than anatomical crowns $(p=0.016)$. Likewise, within enamel antagonists, both axial $(p=0.031)$ and lateral loading $(p=0.025)$ of PEEK specimens resulted in significantly higher material loss values for the flatly configured specimens.

Within the COMP groups, a significantly higher material loss was observed for the flat specimens than for the crown specimens when loaded laterally with steel antagonists $(p<0.001)$ and when loaded axially with enamel antagonists $(p=0.045)$. In contrast, axial loading with steel antagonists led to significantly higher material loss for the COMP crown specimens $(p=0.036)$.

Flat PMMA specimens showed significantly higher material loss than crown specimens after axial loading with enamel $(p=0.014)$ as well as with steel antagonists $(p=0.036)$.

On the antagonist side, none of the following fixed effects showed an impact on material loss: CAD/CAM polymer material $(p=0.245)$, antagonist material $(p=0.438)$, force application $(p=0.309)$ and specimen geometry $(p=0.243)$. Therefore, no further statistical analyses on this aspect were carried out. Representative SEM pictures of the abraded surfaces are shown in Table 4. 


\section{Discussion}

The wear behavior of three types of CAD/CAM polymer materials (thermoplastic PEEK, nanohybrid composite and PMMA-based material) was evaluated in this laboratory study. The material loss with respect to the antagonist (enamel or steel), the specimen configuration (flat or crown) and the direction of force application (axial or lateral) was assessed.

Both, polymer material and application force had a significant impact on the wear results: All PEEK specimens showed significantly lower material wear than COMP and PMMA specimens when loaded laterally regardless of configuration and antagonist material. Within the axial loaded groups this was only true for the flat specimens tested with enamel antagonists. Therefore, the null hypothesis stating that the wear of CAD/CAM resins is similar to that of PEEK was rejected. COMP specimens showed significantly higher wear values than the PMMA ones with regard to the following to the flat specimens when specimens were axially loaded with enamel antagonists and when loaded laterally with steel antagonists, respectively.

Preferably, the wear behavior of materials for dental application should be similar to that of enamel. Thus, restorative materials should not damage natural antagonistic teeth [33]. When assessing the antagonist's wear, no impact of CAD/CAM polymer material, antagonist material, force application and specimen geometry was found. Consequently, the null hypothesis stating that the antagonist wear of all tested groups is similar, regardless on the test method used, was accepted.

In the present study, among the tested polymers, PEEK specimens showed the lowest wear rates both for PEEK itself - when tested laterally - as well as the antagonist enamel. Material wear leads to surface roughness promoting biofilm formation. Hahnel et al. investigated this process on PEEK, zirconia and titanium surfaces and found equal or less biofilm formation on PEEK surface [34]. The wear behavior of a resin-based CAD/CAM-nanocomposite and even a direct nanocomposite material was not significantly different from that of human enamel [36]. Yet, these resin-based materials had significantly higher material wear than the all-ceramic CAD/CAM-materials, which were also investigated. Yet, also two temporary acrylic polymer CAD/CAM materials were investigated (TelioCAD and CAD-Temp) exhibiting significantly higher wear values than enamel and all of the

other tested restorative materials [35]. A CAD/CAM polymer containing $85 \mathrm{wt} \%$ 
ultrafine zirconia-silica ceramic particles (MZ100) showed significantly higher material wear, yet exhibiting a significantly smaller amount of enamel wear when compared to ceramic materials [10]. In contrast to ceramics, no enamel cracks were caused by the CAD/CAM resins [3]. This is corroborated by the findings of of the present study.

Corresponding to the present antagonist wear results, no differences in antagonist wear between flat and crown specimens were found when investigating ceramic specimens with the so-called Ivoclar method [16]. In another study, however, enamel antagonist wear was more than doubled up for flat specimens in comparison to the inlay ones [36]. This shows that the results may depend on different set-up characteristics.

The volume loss of composite artificial teeth compared to PMMA ones was found to be similar when using steel antagonists [37]. Higher wear resistance of composite resin teeth compared to acrylic resin teeth was observed in some in vitro studies when loading with enamel antagonists [38,39]. In the COMP groups with the test conditions described at the beginning (axially loaded with enamel antagonist and laterally loaded with steel antagonist) as well as in all groups with PEEK showing the significant lowest values, the specimen geometry had a significant impact: crown specimens exhibited lower wear values than flat ones. Similar test results regarding specimen geometry were obtained in another study: polished Empress specimens showed more than $100 \%$ wear of the flat specimens compared to that of inlays (Zurich wear data of the round robin test) [36]. Yet, in both studies only ceramic materials were investigated. The reason for the higher material wear of flat specimens might be the higher strain distribution in flat specimens than in crown ones [16].

The steel antagonists caused significantly higher material wear than the enamel ones for all flat configured specimens with one exception (PEEK loaded axially). No impact of antagonist material was observed when the specimens were configured as crowns except for the laterally loaded resin groups. In the literature, there is no agreement on the influence of antagonist material kind on wear simulation tests. In most studies prepared enamel from extracted molars is used [16]. Stainless steel is not a typical antagonist in the oral cavity. Though, this material is being applied time and again for the wear evaluation of artificial resin teeth $[37,38]$. Nevertheless, stainless steel was chosen as further antagonist material for the present study. 
Generally, the lateral force application led to significantly higher material loss than the axial load application except for two crown groups (PEEK tested with steel antagonist and COMP with enamel antagonist). In the present study, the specimens were also loaded laterally as the specimens are only subjected to micro-fatigue stress when sliding of the antagonists is simulated [16]. Correspondingly to the Ivoclar method, a lateral movement of $0.7 \mathrm{~mm}$ was applied. This loading procedure increased the wear of a specific composite material by about eight times [17].

A higher standard deviation was observed within groups with lateral movements. The reason for this finding could be the fact that a lateral load induces higher stress on the material. Especially materials with lower elasticity moduli such as polymers tested in this study may tend more easily deform and irregularly displace.

Any comparisons of results of the present with other studies should be made with caution as the test parameters may significantly differ from one study to the other. A study investigated the material wear of 10 direct resin composites when aged in five different wear simulation devices (ACTA, Zurich, Alabama, MTS and OHSU) and found no comparable results [17]. However, for simulating the complex oral wear, both in-vitro and in-vivo investigations are crucial. Yet, in-vitro wear tests show merely little correlation with clinical data [40]. In general, material loss under clinical conditions is lower than in laboratory studies. In addition, there is also a high variability of results regardless of the kind of study. Nonetheless, carrying out in-vitro studies enables testing under standardized conditions making a comparative evaluation of different materials possible [41]. For verification of the reliability of the attained wear results, clinical evaluations are required and envisaged.

\section{Conclusion}

Within the limitation of the present laboratory study, the following conclusion can be made:

- Wear of PEEK is lower than that of composite and PMMA-based materials when tested laterally

- The antagonist wear shows no impact of restoration material. 


\section{Acknowledgements}

The authors would like to thank nt-trading, Ivoclar Vivadent, and Merz Dental for supporting this study with materials. 


\section{REFERENCES}

1. Magne P. Composite resins and bonded porcelain: the postamalgam era? J Calif Dent Ass 2006;34:135-47.

2. Edelhoff D, Beuer F, Schweiger J, Brix O, Stimmelmayr M, Güth JF. CAD/CAMgenerated high-density polymer restorations for the pretreatment of complex cases: a case report. Quintessence Int 2012;43:457-67.

3. Stawarczyk B, Özcan M, Trottmann A, Schmutz F, Roos M, Hämmerle C. Twobody wear rate of CAD/CAM resin blocks and their enamel antagonists. J Prosthet Dent 2013;109:325-32.

4. Alt V, Hannig M, Wostmann B, Balkenhol M. Fracture strength of temporary fixed partial dentures: CAD/CAM versus directly fabricated restorations. Dent Mater 2011;27:339-47.

5. Attia A, Abdelaziz KM, Freitag S, Kern M. Fracture load of composite resin and feldspathic all-ceramic CAD/CAM crowns. J Prosthet Dent 2006;95:117-23.

6. Stawarczyk B, Ender A, Trottmann A, Özcan M, Fischer J, Hämmerle CH. Loadbearing capacity of CAD/CAM milled polymeric three-unit fixed dental prostheses: effect of aging regimens. Clin Oral Investig 2012;16:1669-77.

7. Fischer J, Roeske S, Stawarczyk B, Hämmerle $\mathrm{CH}$. Investigations in the correlation between Martens hardness and flexural strength of composite resin restorative materials. Dent Mater J 2010;29:188-92.

8. Stawarczyk B, Sener B, Trottmann A, Roos M, Özcan M, Hämmerle CH. Discoloration of manually fabricated resins and industrially fabricated CAD/CAM blocks versus glass-ceramic: effect of storage media, duration, and subsequent polishing. Dent Mater J 2012;31:377-83. 
9. Carvalho AO, Bruzi G, Giannini M, Magne P. Fatigue resistance of CAD/CAM complete crowns with a simplified cementation process. J Prosthet Dent 2014;111:310-7.

10. Kunzelmann KH, Jelen B, Mehl A, Hickel R. Wear evaluation of MZ100 compared to ceramic CAD/CAM materials. Int J Comput Dent 2001;4:171-84.

11. Stawarczyk B, Özcan M, Schmutz F, Trottmann A, Roos M, Hämmerle CH. Twobody wear of monolithic, veneered and glazed zirconia and their corresponding enamel antagonists. Acta Odontol Scand 2013;71:102-12.

12. Anusavice KJ. Degradability of dental ceramics. Adv Dent Res 1992;6:82-9.

13. Monasky GE, Taylor DF. Studies on the wear of porcelain, enamel, and gold. J Prosthet Dent 1971;25:299-306.

14. Ekfeldt A, Fransson B, Soderlund B, Oilo G. Wear resistance of some prosthodontic materials in vivo. Acta Odontol Scand 1993;51:99-107.

15. Ekfeldt A, Oilo G. Wear of prosthodontic materials--an in vivo study. J Oral Rehabil 1990;17:117-29.

16. Heintze SD, Cavalleri A, Forjanic M, Zellweger G, Rousson V. Wear of ceramic and antagonist--a systematic evaluation of influencing factors in vitro. Dent Mater 2008;24:433-49.

17. Heintze SD. How to qualify and validate wear simulation devices and methods. Dent Mater 2006;22:712-34.

18. Freiberg RS, Ferracane JL. Evaluation of cure, properties and wear resistance of Artglass dental composite. Am J Dent 1998;11:214-8.

19. Kurtz SM and Devine JN. PEEK biomaterials in trauma, orthopedic, and spinal implants. Biomaterials 2007;28:4845-4869. 
20. Stawarczyk B, Beuer F, Wimmer T, Jahn D, Sener B, Roos M and Schmidlin PR. Polyetheretherketone-a suitable material for fixed dental prostheses? J Biomed Mater Res B Appl Biomater 2013;101:1209-1216.

21. Stawarczyk B, Eichberger M, Uhrenbacher J, Wimmer T, Edelhoff D, Schmidlin PR. Three-unit reinforced polyetheretherketone composite FDPs: Influence of fabrication method on loadbearing capacity and failure types. J Dent Mater 2015;34:7-12.

22. Uhrenbacher J, Schmidlin PR, Keul C, Eichberger M, Roos M, Gernet W, Stawarczyk B. The effect of surface modification on the retention strength of polyetheretherketone crowns adhesively bonded to dentin abutments. J Prosthet Dent 2014;112:1489-97.

23. Stawarczyk B, Jordan P, Schmidlin PR, Roos M, Eichberger M, Gernet W, Keul C. PEEK surface treatment effects on tensile bond strength to veneering resins. J Prosthet Dent 2014;112:1278-88.

24. Stawarczyk B, Keul C, Beuer F, Roos M, Schmidlin PR. Tensile bond strength of veneering resins to PEEK: impact of different adhesives. Dent Mater J 2013;32:4418.

25. Schmidlin PR, Stawarczyk B, Wieland M, Attin T, Hämmerle CH, Fischer J. Effect of different surface pre-treatments and luting materials on shear bond strength to PEEK. Dent Mater 2010;26:553-9.

26. Kern M, Lehmann F. Influence of surface conditioning on bonding to polyetheretherketon (PEEK). Dent Mater. 2012;28(12):1280-1283.

27. Fuhrmann G, Steiner M, Freitag-Wolf S, Kern M. Resin bonding to three types of polyaryletherketones (PAEKs)-durability and influence of surface conditioning. Dent Mater 2014;30:357-63. 
28. Stawarczyk B, Bahr N, Beuer F, Wimmer T, Eichberger M, Gernet W, Jahn D, Schmidlin PR. Influence of plasma pretreatment on shear bond strength of selfadhesive resin cements to polyetheretherketone. Clin Oral Investig 2014;18:163-70.

29. Rosentritt M, Preis V, Behr M, Sereno N, Kolbeck C. Shear bond strength between veneering composite and PEEK after different surface modifications. Clin Oral Investig 2015;19:739-44.

30. Hallmann L, Mehl A, Sereno N, Hämmerle CHF. The improvement of adhesive properties of PEEK through different pre-treatments. Appl Surf Sci 2012;258:7213-8.

31. Sproesser O, Schmidlin PR, Uhrenbacher J, Eichberger M, Roos M and Stawarczyk B. Work of adhesion between resin composite cements and PEEK as a function of etching duration with sulfuric acid and its correlation with bond strength values. Int J Adhes Adhes 2014;54:184-90.

32. Beuer F, Stimmelmayr M, Güth JF, Edelhoff D, Naumann M. In vitro performance of full-contour zirconia single crowns. Dent Mater. 2012;28:449-456.

33. Preis V, Behr M, Kolbeck C, Hahnel S, Handel G, Rosentritt M. Wear performance of substructure ceramics and veneering porcelains. Dent Mater $2011 ; 27: 796-804$

34. Hahnel S, Wieser A, Lang R, Rosentritt M. Biofilm formation on the surface of modern implant abutment materials. Clin Oral Implants Res 2014 [epub ahead].

35. Mörmann WH, Stawarczyk B, Ender A, Sener B, Attin T, Mehl A. Wear characteristics of current aesthetic dental restorative CAD/CAM materials: two-body wear, gloss retention, roughness and Martens hardness. J Mech Behav Biomed Mater 2013;20:113-25.

36. Heintze SD, Barkmeier WW, Latta MA, Rousson V. Round robin test: wear of nine dental restorative materials in six different wear simulators - supplement to the round robin test of 2005. Dent Mater 2011;27:e1-9. 
37. Hahnel S, Behr M, Handel G, Rosentritt M. Two-body wear of artificial acrylic and composite resin teeth in relation to antagonist material. J Prosthet Dent 2009;101:269-78.

38. Ghazal M, Yang B, Ludwig K, Kern M. Two-body wear of resin and ceramic denture teeth in comparison to human enamel. Dent Mater 2008;24:502-7.

39. Hirano S, May KB, Wagner WC, Hacker CH. In vitro wear of resin denture teeth. J Prosthet Dent 1998;79:152-5.

40. Lambrechts P, Debels E, Van Landuyt K, Peumans M, Van Meerbeek B. How to simulate wear? Overview of existing methods. Dent Mater 2006;22:693-701.

41. Rosentritt M, Siavikis G, Behr M, Kolbeck C, Handel G. Approach for valuating the significance of laboratory simulation. J Dent 2008;36:1048-53. 


\section{Tables and Figures}

Table 1 - Summary of products used.

Table 2 - Volume wear of tested restoration materials and their enamel antagonists $\left(\mu \mathrm{m}^{3}\right)$ : Mean (SD), minimum, median, maximum, $95 \%$ confidence intervals $(95 \% \mathrm{Cl})$.

Table 3 - Volume wear of tested restoration materials and their stainless steel antagonists $\left(\mu \mathrm{m}^{3}\right)$ : Mean (SD), minimum, median, maximum, 95\% confidence intervals $(95 \% \mathrm{Cl})$.

Table 4 - Scanning electron microscopy (SEM) images of selected specimens and antagonists at a magnification of 90 .

Fig. 1 - Study design.

Fig. 2 - Specimens during a chewing simulation.

Fig. 3 - Boxplots of material loss of all groups. 


\section{Tables}

Table 1 - Summary of products used.

\begin{tabular}{lcccc}
\hline Test group & Product name & Abbreviation & Batch Number & Manufacturer \\
\hline Thermoplastic PEEK & Dentokeep & PEEK & 11DK14001 & nt-trading, Karlsruhe, Germany \\
\hline experimental CAD/CAM nanohybrid composite & - & COMP & HT A2/C14 28923 & Ivoclar Vivadent, Schaan, Lichtenstein \\
\hline PMMA-based CAD/CAM material & artBloc Temp & PMMA & 44308 & Merz Dental, Lütjenburg, Germany \\
\hline
\end{tabular}

Table 2 - Volume wear of tested restoration materials and their enamel antagonists $\left(\mu \mathrm{m}^{3}\right)$ : Mean (SD), minimum, median, maximum, $95 \% \mathrm{Confidence} \mathrm{intervals}(95 \%$ Cl).

\begin{tabular}{|c|c|c|c|c|c|c|c|c|}
\hline \multirow{2}{*}{ Test group } & \multirow{2}{*}{$\begin{array}{c}\text { Configuration } \\
\text { Flat (F), } \\
\text { Crown (C) }\end{array}$} & \multirow{2}{*}{$\begin{array}{c}\text { Lateral } \\
\text { Movement }\end{array}$} & \multicolumn{3}{|c|}{ Material wear $\left[10^{6} \mu \mathrm{m}\right]$} & \multicolumn{3}{|c|}{ Antagonist enamel wear $\left[10^{6} \mu \mathrm{m}\right]$} \\
\hline & & & Mean (SD) & Min & Max & Mean (SD) & Min & Max \\
\hline \multirow{4}{*}{ PEEK } & \multirow{2}{*}{$\mathrm{F}$} & yes & $-45.36(12.59)$ & -27.63 & -64.38 & $-2.88(2.09)$ & -0.51 & -6.17 \\
\hline & & no & $-3.11(3.23)$ & -1.28 & -4.53 & $-18.86^{*}(23.96)$ & -0.08 & -76.56 \\
\hline & \multirow{2}{*}{ C } & yes & $-29.48(18.99)$ & -1.63 & -58.06 & $-122.25(1.13)$ & -29.56 & -321.68 \\
\hline & & no & $-1.94^{*}(22.95)$ & -2.31 & -81.85 & $-0.37^{*}(0.37)$ & -0.01 & -1.83 \\
\hline \multirow{4}{*}{ COMP } & \multirow{2}{*}{$\mathrm{F}$} & yes & $-186^{*}(193.37)$ & -57.79 & -600 & $-1.47(1.20)$ & -0.07 & -3.26 \\
\hline & & no & $-39.44(28.98)$ & -0.56 & -89.91 & $-12.29^{*}(12.81)$ & -0.21 & -47.17 \\
\hline & \multirow{2}{*}{ C } & yes & $-118(112.70)$ & -9.79 & -300 & $-151.47(6.38)$ & -61.31 & -324.93 \\
\hline & & no & $-19.59(12.36)$ & -6.25 & -44.76 & $-0.88^{*}(0.88)$ & -0.01 & -5.65 \\
\hline \multirow{4}{*}{ PMMA } & \multirow{2}{*}{$\mathrm{F}$} & yes & $-144(79.89)$ & -46.43 & -300 & $-0.75^{*}(0.79)$ & -0.27 & -3.20 \\
\hline & & no & $-15.05(7.47)$ & -5.23 & -30.76 & $-10.30^{*}(12.61)$ & -0.17 & -47.17 \\
\hline & \multirow{2}{*}{ C } & yes & $-120(85.86)$ & -26.06 & -300 & $-185.17(0.72)$ & -95.81 & -261.53 \\
\hline & & no & $-27.14(13.79)$ & -9.36 & -55.81 & $-0.79^{*}(1.72)$ & -0.01 & -4.62 \\
\hline
\end{tabular}


Table 3 - Volume wear of tested restoration materials and their stainless steel antagonists $\left(\mu \mathrm{m}^{3}\right.$ ): Mean (SD), minimum, median, maximum, $95 \%$ confidence intervals $(95 \% \mathrm{Cl})$.

\begin{tabular}{|c|c|c|c|c|c|c|c|c|}
\hline \multirow{2}{*}{ Test group } & \multirow{2}{*}{$\begin{array}{c}\text { Configuration } \\
\text { Flat (F), } \\
\text { Crown (C) }\end{array}$} & \multirow{2}{*}{$\begin{array}{c}\text { Lateral } \\
\text { Movement }\end{array}$} & \multicolumn{3}{|c|}{ Material wear $\left[10^{6} \mu \mathrm{m}\right]$} & \multicolumn{3}{|c|}{ Antagonist steel wear $\left[10^{6} \mu \mathrm{m}\right]$} \\
\hline & & & Mean (SD) & Min & Max & Mean (SD) & Min & Max \\
\hline \multirow{4}{*}{ PEEK } & \multirow{2}{*}{$\mathrm{F}$} & yes & $-80.72(43.35)$ & -39.67 & -200 & $-12.2(7.83)$ & -111.7 & -29.1 \\
\hline & & no & $-3.62(0.99)$ & -1.68 & -5.39 & $18900^{*}(5116)$ & -0.07 & -200000 \\
\hline & \multirow{2}{*}{$C$} & yes & $-43.81(17.97)$ & -24.40 & -73.78 & $-0.47^{*}(0.68)$ & -0.04 & -2.41 \\
\hline & & no & $-33.23^{*}(52.40)$ & -0.42 & -200 & $-4.38(1.69)$ & -1.46 & -6.90 \\
\hline \multirow{4}{*}{ COMP } & \multirow{2}{*}{$\mathrm{F}$} & yes & $-653(8.42)$ & -600 & -800 & $-48.8(7.67)$ & -37.5 & -63.6 \\
\hline & & no & $-5.55^{*}(9.32)$ & -0.44 & -3.41 & $-11.11(3.47)$ & -5.52 & -16.32 \\
\hline & \multirow{2}{*}{$C$} & yes & $-379(121.53)$ & -200 & -600 & $-0.06(0.08)$ & 0 & -0.21 \\
\hline & & no & $-31.41(27.71)$ & -2.56 & -82.18 & $-0.31^{*}(0.51)$ & -0.01 & -1.89 \\
\hline \multirow{4}{*}{ PMMA } & \multirow{2}{*}{$F$} & yes & $-310(43.97)$ & -200 & -400 & $-22.3^{*}(17.246)$ & -10.8 & -74.1 \\
\hline & & no & $-5.08(2.98)$ & -0.13 & -10.48 & $-43.68^{*}(49.59)$ & -9.51 & -200 \\
\hline & \multirow{2}{*}{ C } & yes & $-308(227.84)$ & -40.51 & -800 & $-0.57(0.39)$ & -0.01 & -1.16 \\
\hline & & no & $-12.61(10.73)$ & -0.09 & -37.54 & $-1.54^{*}(3.01)$ & -2.66 & -7.96 \\
\hline
\end{tabular}


Table 4 - Scanning electron microscopy (SEM) images of selected specimens and antagonists at a magnification of 90.

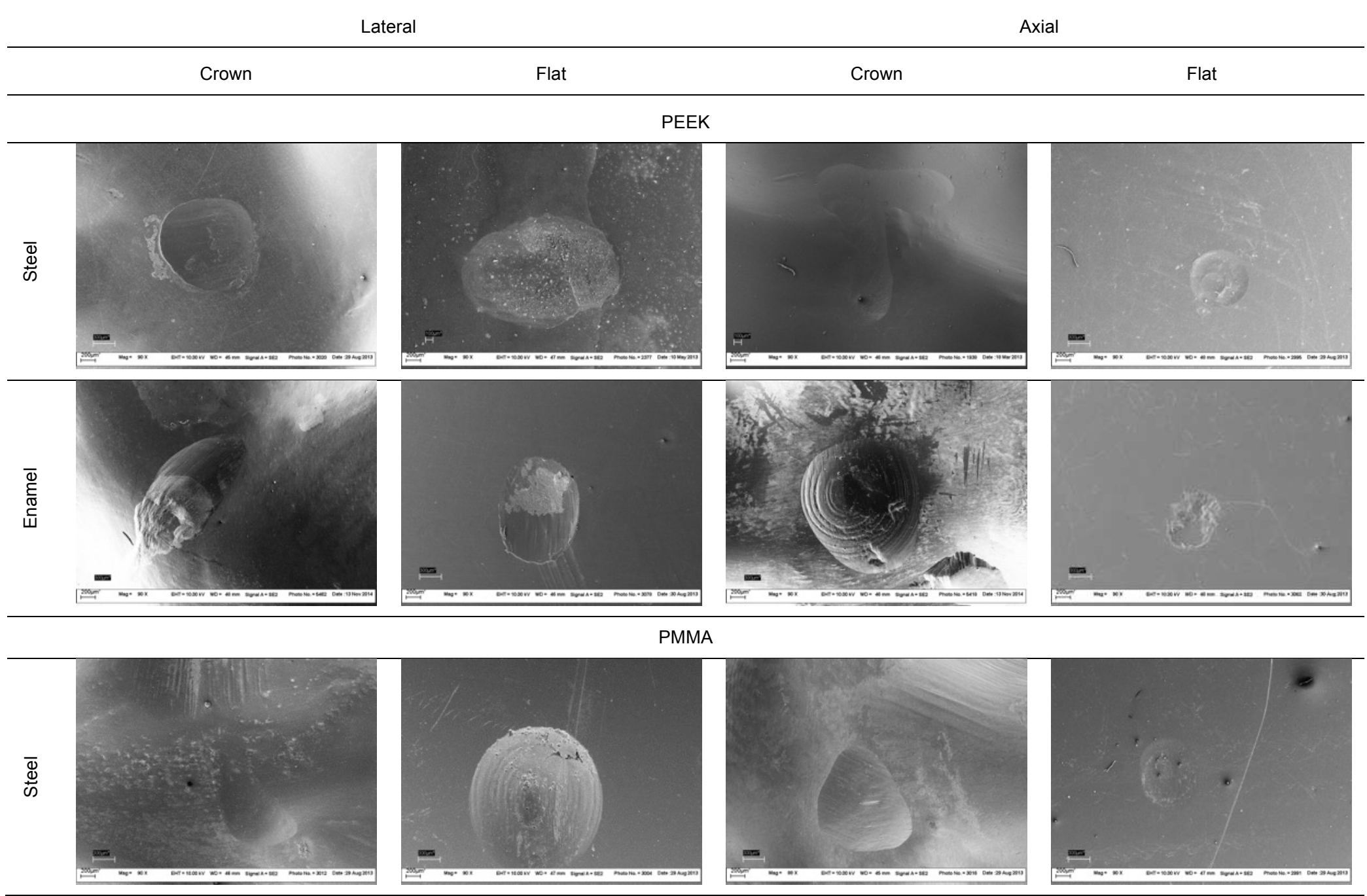



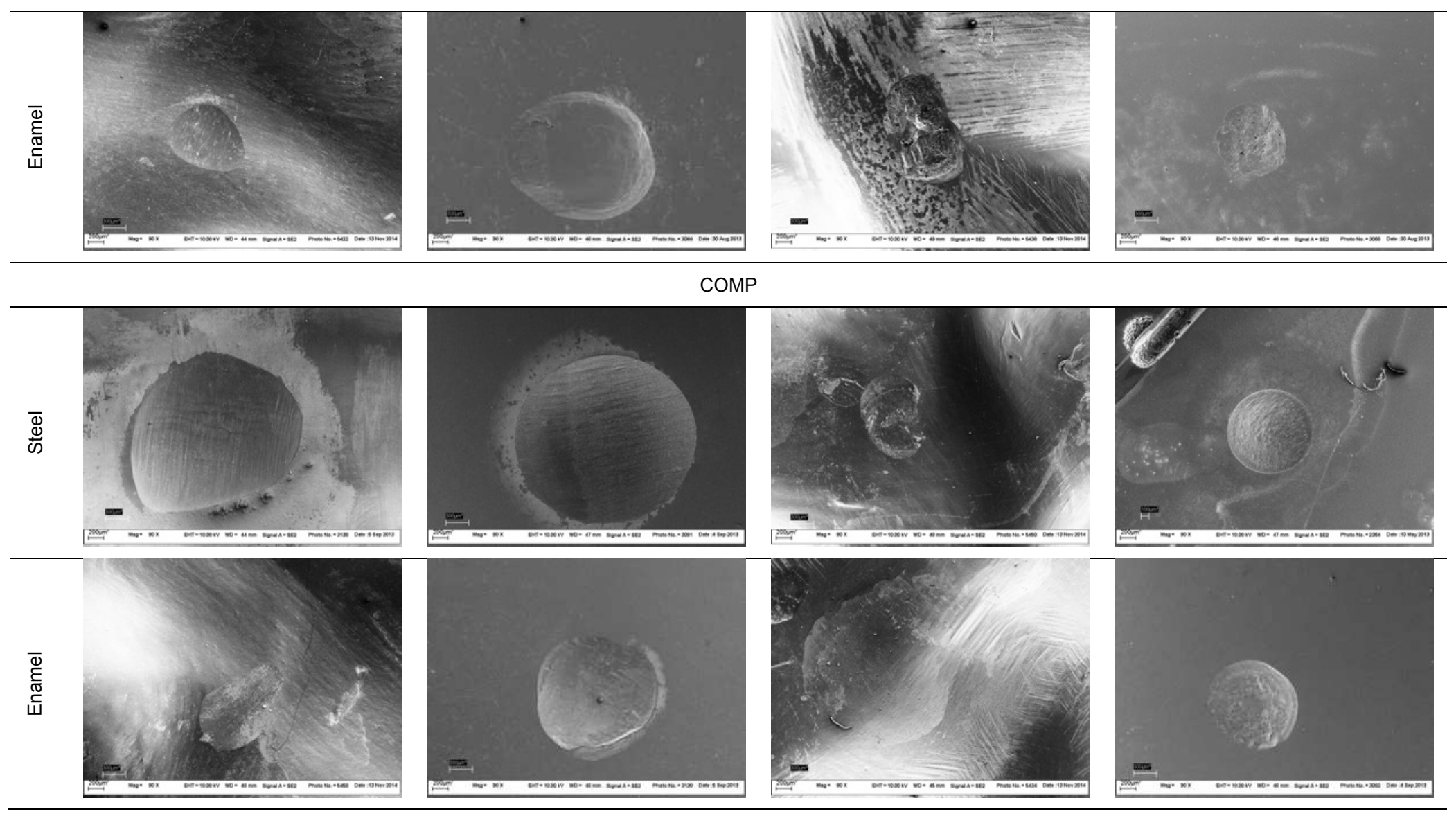
